\title{
Evaluating College Quarterbacks as They Enter the National
}

\section{Football League Draft}

\author{
Matthew L. Lavoie ${ }^{1} \&$ Paul D. Berger ${ }^{2 *}$ \\ ${ }^{1}$ Marketing Analytics Program, Bentley University, Waltham, MA, USA \\ ${ }^{2}$ Marketing Department, Bentley University, Waltham, MA, USA \\ *Paul D. Berger, E-mail: PBerger@Bentley.edu
}

\begin{abstract}
The National football League (NFL) in the United States has become a quarterback-centric league, where an elite quarterback is needed to win a Super Bowl. This paper will aim to provide statistical insight into how to project which college quarterback prospects will have the most successful NFL careers. We specifically focus on two quarterbacks, Jameis Winston and Marcus Mariotta, who, respectively, were the first and second choice in the first round of the NFL draft recently, in May, 2015. However, our methodology is applicable to other quarterback draftees, and with modest adaptation, to evaluating players at other positions.
\end{abstract}

Keywords

NFL, quarterback comparisons, stepwise regression analysis, binary logistic regression analysis, decision tree analysis

\section{Introduction}

Over the last decade, the National Football League (NFL) has evolved into a pass-dominant league. In 2014, total league-wide passing yards were up $12.4 \%$ from 2004 totals. Some of this increase can be attributed to rule changes that penalize defenders for contact with receivers, a tactic many believe the NFL implemented to increase scoring, and thus, viewership. The increase in total league-wide passing yards may possibly also be ascribed to improved scouting and offensive game-planning. One element that cannot be overlooked, however, is the quarterback, himself. Quarterbacks are receiving advanced training at an early age and are being groomed into franchise-caliber players. This development has essentially turned the NFL into the aforementioned quarterback-centric league.

In a quarterback-centric league, a team must possess an elite (Note 1) quarterback in order to win a Super Bowl championship. Nine of the last ten Super Bowl champion teams were led by quarterbacks who were acquired as a rookie on draft day, via either draft pick or trade. Because elite veteran quarterbacks are rarely available by trade or free agency, the decision of which quarterback a team drafts carries enormous magnitude. Drafting the right quarterback does not guarantee a team that they will win a Super Bowl or even play in one, but it is a major step in the right direction. Drafting the 
wrong quarterback, on the other hand, generally results in a team out of Super Bowl contention for several years into the future.

The problem is: how does a team know which quarterback they should draft? Recently, in May, 2015, the Tampa Bay Buccaneers held the first pick in the NFL draft. They were a team in desperate need of a quarterback. According to most analysts, only two quarterbacks in the draft: Florida State's Jameis Winston and Oregon's Marcus Mariota have a "decently high" probability of being an elite quarterback. As was expected by many, the Tampa Bay Buccaneers drafted Winston as the first choice in the draft. The Tennessee Titans, who had the second choice in the draft, chose Mariota. While the majority opinion indicated that Winston would be a superior quarterback to Mariota, there was nowhere near unanimity on the subject. One purpose of this paper is to predict which of the two quarterbacks will have a more successful NFL career.

The methodology used in this paper, however, can be applied to any quarterback in the recent draft or subsequent drafts; in the recent draft, there were several quarterbacks chosen in later rounds of the draft; the clear presumption was that each of these "later choices" were overwhelmingly less likely than either Winston or Mariota to be an elite quarterback in the NFL.

We should add that there have been spectacular "errors"-in both directions - made in the past with respect to assessments of how elite a quarterback will be in the NFL. Two of the largest, incorrect assessments in one direction (dramatically overestimating how elite a quarterback will be) had to do with Ryan Leaf and JaMarcus Russell. Leaf was drafted second in 1998, and at the time, was thought by some to be a better prospect than the first choice, Peyton Manning; Manning is acknowledged by virtually everyone as one of the top 10 NFL quarterbacks of all time. Leaf was a total bust. Russell was drafted first in 2007, and ended up being a total bust; while it is true that there were no other quarterbacks taken in that draft that were even above average (never mind elite), there were players at other positions taken later in the draft that are now elite players (e.g., Calvin Johnson, chosen second, who is acknowledged by most NFL experts to be one of the top 2 or 3 receivers in the NFL). In the other direction (dramatically underestimating how elite a quarterback will be), we have at least one glaring error, Tom Brady. Brady was not drafted until the 6th round and many quarterbacks were drafted ahead of him; many, if not most, NFL experts agree that Brady is in the top five quarterbacks of all time. In spite of these errors in judgment, we believe that statistical analysis can be used to gain insight, albeit not perfection, about whether a quarterback will be elite in the NFL.

\section{Method}

In order to determine the future success at the NFL level of college quarterbacks we compiled data collected by the National Collegiate Athletic Association (NCAA), the NFL Draft Scouting Combine (a pre-draft NFL-organized event that measures selected variables about each attendee-the large majority of those college football players who expect to, or hope to, get drafted by an NFL team), and NFL, itself, from 1999-2014 (pro-football-reference, 2015; sports-reference, 2015; 
nflcombineresults-reference, 2015). In total, the data include statistics for all $(\mathrm{n}=69)$ quarterbacks drafted during the 14-year period, 1999-2013, who (1) played at major divison-1 colleges and universities the highest level of college sports, and including the vast majority of draftees and (2) have started a minimum of 10 games in the NFL (It was deemed that data on players that played fewer than 10 NFL games were not sufficiently reliable to be appropriate for this study).

\subsection{Variables}

The variables include:

CollegeGames: number of college games a player started at quarterback,

CollegePass $Y d s G m$ : number of pass yards per game a quarterback accounted for in college,

CollegeRushYdsGm: number of rush yards per game a quarterback accounted for in college,

CollegePassTDsGm: number of passing touchdowns per game a quarterback accounted for in college, CollegeRushTDsGm: number of rushing touchdowns per game a quarterback accounted for in college, CollegeInts Gm: number of interceptions per game a quarterback threw in college,

CompPercent: a quarterback's completion percentage in college,

Height: a quarterback's height in inches as measured at the NFL Scouting Draft Combine,

Weight: a quarterback's weight in pounds as measured at the NFL Scouting Draft Combine,

FortyYdDash: a quarterback's time in seconds in the 40 yard dash, measured at the NFL Draft Scouting Draft Combine,

Wonderlic: a quarterback's score (0-50) on the Wonderlic (intelligence) test, measured at the NFL Scouting Draft Combine,

WinPercent: a quarterback's career winning percentage in the NFL,

ProBowl: defined as 0 if the quarterback was not selected to the Pro Bowl (the NFL name of the "All-Star" game) in his first three years in the NFL, 1 if he was selected to the Pro Bowl in his first three years in the NFL,

Playoffs: defined as 0 if the quarterback did not start a playoff game (i.e., the team performed sufficiently well during the season to be allowed to compete afterward for entry to the Super Bowl) in his first three years in the NFL. If he did start a playoff game in his first three years in the NFL, a variety of analyses were run, as described in the next section.

\section{Results}

\subsection{Multiple Stepwise Linear Regression Analysis}

We first ran a stepwise multiple linear regressions with WinPercent as the dependent variable. The independent variables were CompPercent, PassTDsGame, RushTDsGame, CollegeGames, PassYdsGm, RushYdsGm, Height, Weight, FortyDash and Wonderlic.The stepwise results in the Table 1, with n=65 ( 4 of the 69 quarterbacks in the overall sample were not included, since they did not have a Wonderlic score avaiable) indicate that there are only two significant variables at a p-value to enter of .05 and p-value to delete of .10: RushYdsGm and FortyDash. The coefficient for FortyDash is positive, 
indicating that a player, who, in the NFL Draft Scouting Draft, records a slower time to run 40 yards, is predicted to have a higher winning percentage in the NFL. This may seem counterintuitive, but this is likely attributed to slower quarterbacks in general being more polished in terms of passing the ball in the pocket (Note 2). The vast majority of the top quarterbacks of all time in the NFL exhibit (ed) a style of not being able to run very fast with the football (relatively speaking), but, rather, being a better passer and using superior judgment when to pass and to whom to pass. After all, without "other skills", the quarterback would not be in demand and would not have been drafted in the first place.

The coefficient for Rush $Y d s \mathrm{Gm}$ is also positive, indicating that agility in a quarterback positively correlated with winning percentage. A quarterback who has a slower Forty Dash time and a high Rush $Y d s G m$ would be predicted to have a higher NFL winning percentage. This speaks to the importance of "escapability", which is a quarterback's ability to elude defenders and pick up yards on the ground without using speed as his primary asset. This skill certainly has more longevity in a quarterback's career than speed, itself. Interestingly enough, none of the pure passing statistics were significant.

\section{Table 1. Stepwise Regression Results}

\begin{tabular}{|c|c|c|c|c|c|c|}
\hline \multicolumn{7}{|c|}{ Coefficients $^{a}$} \\
\hline \multirow{2}{*}{\multicolumn{2}{|c|}{ Model }} & \multicolumn{2}{|c|}{ Unstandardized Coefficients } & $\begin{array}{l}\text { Standardized } \\
\text { Coefficients }\end{array}$ & \multirow[b]{2}{*}{$\mathrm{t}$} & \multirow[b]{2}{*}{ Sig. } \\
\hline & & $\mathrm{B}$ & Std. Error & Beta & & \\
\hline \multirow[t]{2}{*}{1} & (Constant) & .405 & .024 & & 17.249 & .000 \\
\hline & RushYdsGm & .002 & .001 & .300 & 2.494 & .015 \\
\hline \multirow[t]{3}{*}{2} & (Constant) & -1.466 & .660 & & -2.222 & .030 \\
\hline & RushYdsGm & .005 & .001 & .600 & 3.858 & .000 \\
\hline & FortyDash & .385 & .136 & .442 & 2.837 & .006 \\
\hline
\end{tabular}

a. Dependent Variable: WinPercent

The resulting formula from the stepwise regression (last and most important step) is:

$$
\text { WinPercent }=-1.466+.005 \text { RushYdsGm+.385FortyDash }
$$

The predictions for our two "special" quarterbacks being directly compared are:

Jameis Winston

$$
\begin{aligned}
& \text { WinPercent }=-1.466+.005 \text { RushYdsGm(10.5) }+.385 \text { FortyDash(4.97) } \\
& \text { WinPercent }=.500
\end{aligned}
$$

Marcus Mariota

$$
\begin{aligned}
& \text { WinPercent }=-1.466+.005 \text { RushYdsGm(54.6)+.385FortyDash(4.52) } \\
& \text { WinPercent }=.547
\end{aligned}
$$

So, as can be seen, our initial analysis would predict Marcus Mariota to have a (what would be viewed as substantially) higher winning percentage than Jameis Winston.

\subsection{Binary Logistic Regression Analysis}

The next analysis we performed was a binary logistic regression with Playoffs used as the dependent variable and Comp Percent, Pass TDs Game, Rush TDs Game, College Games, Pass Yds Gm, Rush Yds 
Gm, Height, Weight, Forty Dash, Wonderlic and Pro Bowl used as independent variables. This analysis (again, with $\mathrm{n}=65$ ) was conducted to see which variables most highly relate to whether a quarterback starts a playoff game within his first three seasons as a pro (the definition of Playoffs). The cut value used for the test was .60. The resulting model correctly predicted $97 \%$ of the quarterbacks who did not make the playoffs in their first three seasons in the NFL. However, it correctly predicted only $57 \%$ of the quarterbacks who made the playoffs in their first three seasons. Overall, it got $80 \%$ of the predictions correct. See the top section of Table 2.

The most (and only) significant variable in the model $(\mathrm{p}=.002)$ is ProBowl. See the bottom section of Table 2. Quarterbacks that are elected to at least one Pro Bowl (recall: essentially, to participate in the All-Star game) in their first three seasons are far more likely to make the playoffs in their first three seasons than quarterbacks who are not elected to the Pro Bowl in their first three seasons, holding all other variables in the equation constant. In truth, this, by itself, is not a very informative result for two reasons (1) indeed, one might argue that the "cause and effect" route behind this relationship is that a quarterback who plays well enough to lead his team to the playoffs typically has played well enough to be elected to the Pro Bowl; (2) we do not know at the time of the draft whether a quarterback will end up being chosen to participate in the Pro Bowl. None of the other variables are even remotely close to being significant by traditional standards.

Table 2. Binary Logistic Regression Results

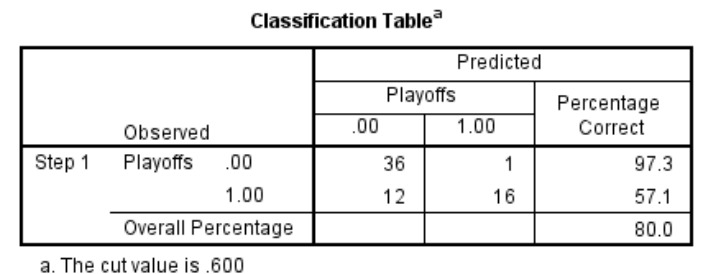

\begin{tabular}{|c|c|c|c|c|c|c|c|}
\hline \multicolumn{8}{|c|}{ Variables in the Equation } \\
\hline & & $\bar{B}$ & S.E. & Wald & $d f$ & Sig. & $\operatorname{Exp}(B)$ \\
\hline \multirow[t]{13}{*}{ Step $1^{\text {a }}$} & CollegeGames & -.005 & .041 & .014 & 1 & .906 & .995 \\
\hline & CompPercent & -.001 & .102 & .000 & 1 & .995 & .999 \\
\hline & PassTDsGame & -1.281 & 1.411 & .824 & 1 & .364 & .278 \\
\hline & RushTDsGame & 1.607 & 3.142 & .262 & 1 & .609 & 4.989 \\
\hline & IntsGame & -2.160 & 2.580 & .701 & 1 & .402 & .115 \\
\hline & PassYdsGm & .016 & .017 & .868 & 1 & .352 & 1.016 \\
\hline & RushYdsGm & -.001 & .048 & .000 & 1 & .985 & .999 \\
\hline & Height & -.090 & .271 & .110 & 1 & .740 & .914 \\
\hline & Weight & .028 & .034 & .712 & 1 & .399 & 1.029 \\
\hline & FortyDash & 1.605 & 2.795 & .330 & 1 & .566 & 4.979 \\
\hline & Wonderlic & -.023 & .058 & .159 & 1 & .690 & .977 \\
\hline & ProBowl & 3.495 & 1.138 & 9.427 & 1 & .002 & 32.937 \\
\hline & Constant & -7.555 & 21.853 & .120 & 1 & .730 & .001 \\
\hline
\end{tabular}

a. Variable(s) entered on step 1: CollegeGames, CompPercent, PassTDsGame, RushTDsGame, IntsGame, PassYdsGm, RushYdsGm, Height, Weight, FortyDash, Wonderlic, ProBowl. 


\subsection{Decision-Tree Analysis}

Since ProBowl was such a significant indicator of Playoffs in the previous analysis, the next analysis we conducted was to attempt to predict the drivers of whether the top two quarterbacks picked in the draft (only a few times the first two selections overall!!) will be elected to the Pro Bowl in their first three seasons in the NFL. The method used was a decision-tree analysis, and there were data from all 69 quarterbacks in this analysis. The dependent variable for the decision tree is ProBowl and the independent variables that made it into the tree are CompPercent (recall: completion percent in college) and RushYdsG (number of rushing yards per game in college). According to the decision tree (see Table 3 ), there is only a $5.9 \%$ chance for a quarterback whose completion percentage was less than or equal to $57.15 \%$ in his college career to make the Pro Bowl within his first three seasons in the NFL. Only one player out of the 17 quarterbacks in the dataset with a completion percent below $57.15 \%$ made the Pro Bowl: Michael Vick. On the other hand, if a quarterback had a completion percentage greater than $57.15 \%$ in his college career $(n=52)$, there was a $28.8 \%$ chance $(15$ of the 52$)$ that he made the Pro Bowl within his first three seasons in the NFL. The data for our two "special" quarterbacks: Jameis Winston: $66.0 \%$ pass-completion percentage in college, Marcus Mariota: $66.8 \%$ pass-completion percentage in college.

Clearly, both quarterbacks had pass-completion percentages above the $57.15 \%$ rate, and had just about the same pass completion rate. The rates were well above the 57.15 cutoff, but the analysis did not reveal specifically how the increase above $57.15 \%$ affects the probability of making the Pro Bowl. Other analyses can speak to this issue.

The decision tree also reveals that for those quarterbacks who exceeded the pass-completion rate of $57.15 \%$, another significant "discriminator" was the number of rushing yards per game. Again, see Table 3. If a quarterback who has a completion percentage over $57.15 \%$ rushed for at least 24.492 yards per game in his college career, the probability of making the Pro Bowl in his first 3 seasons in the NFL increases from $28.8 \%$ to $60 \%$ ( 9 out of 15 ). If he rushes for less than or equal to 24.492 yards per game in college, however, the $28.8 \%$ probability becomes only a $16.2 \%$ (6 out of 37 ) probability that he makes the Pro Bowl in his first three seasons in the NFL.

This significant further breakdown speaks to the emergence of the agile quarterback with exceptional passing skills, along with having the agility to run with the football. Russell Wilson, Andrew Luck, Andy Dalton and Cam Newton all fall into the category of above $57.15 \%$ completion percentage and above 24.492 rushing yards per game subset. Not coincidentally, these players all lead their respective teams to the playoffs in the 2014/2015 season.

The data for our two "special" quarterbacks:

Jameis Winston: 10.5 rush yards per game (reducing the $28.8 \%$ to $16.2 \%$ ),

Marcus Mariota: 54.6 rush yards per game (increasing the $28.8 \%$ to $60 \%$ ).

So, as can be seen, this analysis also would predict Marcus Mariota to be the superior choice to Jameis Winston. 
Table 3. Decision-Tree Analysis Results

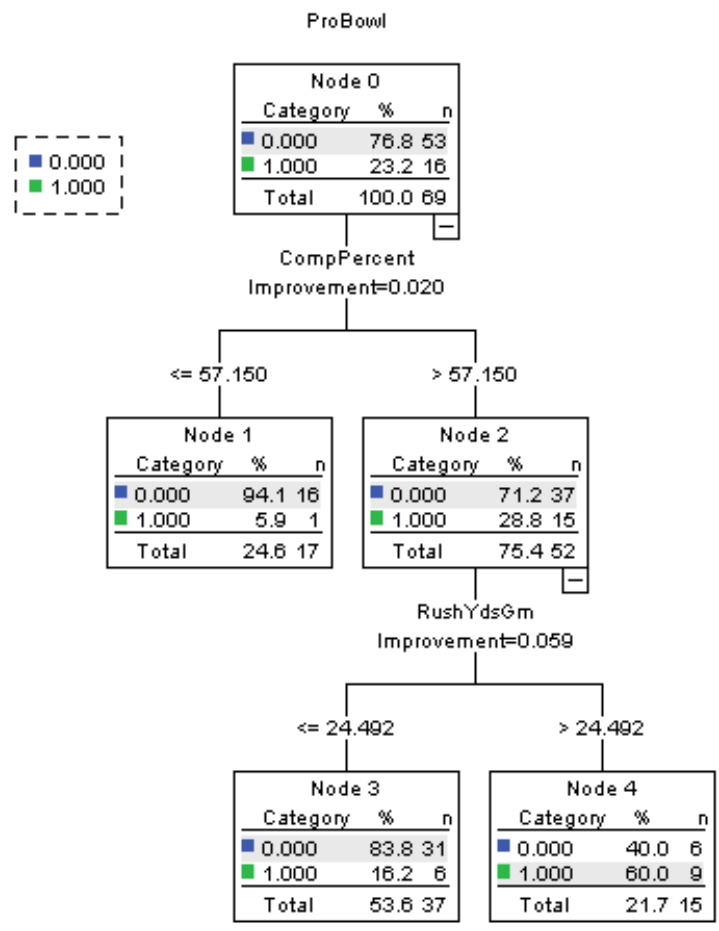

\section{Discussion}

The resulting insights from our analyses indicate that Marcus Mariota will likely be a more successful NFL quarterback than Jameis Winston. Mariota is projected to have a 54.7 winning percentage in his NFL career. Winston on the other hand is projected to have a 50.0 winning percentage. While Winston projects to win only as many games as he loses, Mariota projects to have a slightly better career winning percentage than two-time Super Bowl winning quarterback Eli Manning (through the 2014 season.) Also, the decision-tree analysis that focuses on making the Pro Bowl (which positively correlates with making the playoffs) also heavily favors the choosing of Marcus Mariota over Jameis Winston. Our analysis predicts that Mariota has a $60 \%$ chance of being a Pro Bowler in his first three seasons, while Winston has only a $16.2 \%$ chance.

Interestingly, as noted earlier in the paper, Jameis Winston was the first choice, while Marcus Mariota was the second choice!! There may be good reasons for this-our paper has a number of limitations.

Data that represent the quality of opponents a quarterback faced in college was NOT included in any of our analyses, and may have made the analyses more robust. Furthermore, there are other variables, such as style of offense and number of offensive college teammates that were future NFL players, that may have helped provide additional insight. A number of intangible, qualitative variables are also left out of our analyses. These include "coachability" mental toughness, character, work ethic, improvisational skills, leadership and poise, and likely, several others. Also, one hears reference to the terms "college style" and "pro style" (the latter meaning the NFL), indicating that the skill sets to be an 
effective college football quarterback and effective NFL football quarterback may differ and involve some other, less-easily definable, variables. And, of course, a major "missing variable" in our analyses is the quality of the team the quarterback inherits once he begins his career in the NFL.

When the NFL starts the 2015/2016 season (September, 2015), we will begin to find out whether Jameis Winston was, or Marcus Mariota would have been, the "wise choice".

\section{References}

http://www.nflcombineresults.com

http:/www.pro-football-reference.com

http://www.sports-reference.com

\section{Notes}

Note 1 . There is no precise definition of the word "elite" when it comes to using that label for a quarterback. The term is used often in the NFL, without unanimous agreement as to which quarterbacks it should be applied. The reader can consider the adjective to pertain to a quarterback who is sufficiently superior as to allow his team a reasonable chance of making it to the Super Bowl.

Note 2. The "pocket" is the small area that the quarterback operates in (or, in a way, is trapped in) when the defensive players clashes with the offensive linemen after the football is snapped. When a defensive linemen fights off an offensive linemen and rushes toward the quarterback, and the quarterback moves away from this location to avoid being tackled, the quarterback is said to be "forced out of the pocket". 